\title{
Cost Allocation of Reactive Power Using Matrix Methodology in Transmission Network
}

\author{
Gaurav Gupta, Manisha Dubey, Anoop Ayra \\ Department of Electrical Engineering, Maulana Azad National Institute of Technology, Bhopal, India
}

\begin{tabular}{|c|c|}
\hline Article Info & ABSTRACT \\
\hline Article history: & \multirow{5}{*}{$\begin{array}{l}\text { In the deregulated market environment as generation, transmission and } \\
\text { distribution are separate entities; reactive power flow in transmission lines is } \\
\text { a question of great importance. Due to inductive load characteristic, reactive } \\
\text { power is inherently flowing in transmission line. Hence under restructured } \\
\text { market this reactive power allocation is necessary. In this work authors } \\
\text { presents a power flow tracing based allocation method for reactive power to } \\
\text { loads. MVAr-mile method is used for allocation of reactive power cost. A } \\
\text { sample } 6 \text { bus and IEEE } 14 \text { bus system is used for showing the feasibility of } \\
\text { developed method. }\end{array}$} \\
\hline Received Nov 23, 2017 & \\
\hline Revised Mar 20, 2018 & \\
\hline Accepted May 15, 2018 & \\
\hline Keywords: & \\
\hline Kirchhoff matrix & \\
\hline
\end{tabular}

Copyright () 2018 Institute of Advanced Engineering and Science. All rights reserved.

\section{Corresponding Author:}

Gaurav Gupta,

Department of Electrical Engineering,

Maulana Azad National Institute of Technology,

Bhopal, Madhya Pradesh, India.

Email: gauravmits@gmail.com

\section{INTRODUCTION}

A fair transmission pricing methodology should recover all the cost of the transmission system and provide profit to the transmission utility. So many methodologies have developed in past years for transmission cost allocation in transmission system.

The active power production capability of generator will reduced due to more reactive power. Hence, provision of pricing of reactive power becomes an important issue to be addressed in electricity market as similar to real power pricing [1]. The voltage of the system must be controlled as an component of reactive power supports so, the reliability can achieved but more pricing options required due to unrecovered obtained cost with inclusion of capital cost under scheme proposed in [2]. Reactive power transaction depends on indefinite sources such as susceptance of line, capacitor banks rating, generator capacity, installed FACT devices capacity and so on while real power flows depends on source and direction, Reactive power flow is continuously changing due to variable system operating condition. Further transmission of reactive power does not carry over longer distances because it needed to fulfill local requirements. So while locating reactive sinks, sources of reactive power identification became a big challenge. The scheme based on proportional sharing principal [3-4] offer an effectual computational tool but that concept neither discoverable nor verifiable for loss allocation. Power factor based reactive power costing methods are in traditional use but these methods are inappropriate for the restructured power systems, because they separately charged the cost of reactive power support. In addition, the tariff in current scenario only consider local charges and consumption of reactive power calculated with respect to those variables which do not judge the complete customer's usage [3-6]. Relative electrical distance (RED) idea for transmission charge allocation based on nodal pricing method influences the operation condition and system variable has been discussed in [7]. The majority of the above referred solutions [3-7] show that transmission usage charge also 
having cost of losses in transmission line as in form of their integral part so it does not required separate calculation. The non-acceptability of these methods is due to the long computational time and nonlinearity towards convergence. The Z-bus matrix and modified Y-bus matrix methods treated as circuit-based allocation methods, all the computation in these methods are based on admittance matrix to solved power flow [8], [9].The cost allocation towards line losses based on complex power injection has been addressed in [10]. The virtual flow methodology for assessment of flow of reactive power in transmission network due to different sources and particular load involvement with consideration of counter and loop flows without any difficulty has been addressed in [11]. Flow of electrical power based on tracing approach shows their importance due to its explanatory and comprehensibility in transmission network process. A method based on tracing of electrical power has been reported in [12], [13] which, having assumption that outflow and inflow on nodes are proportionally shared. This permits one to outline power flow in meshed structure. A tracing based reactive power flow is reported by Bialek with upward and downward looking principle. The upward looking principle look at the balancing of incoming flows towards the nodes and the downward looking principle look at the balancing of outgoing flows from the nodes, then compute the power spread among different loads [15].Power flow tracing methods dominate marginal participation method as there is full recovery of cost by tracing flow [16]. It also depends on the Kirchhoff current laws and easy to implements on larger power systems. Moreover it has very less volatility as compared to marginal participation methods. It also provides uniformity and fairness in charge allocation due to depends on actual usage of system [17]. The locational marginal pricing for congestion cost with FACT controller by real power rescheduling for pool based transaction has been discussed in [18]. Determination of generator contribution can be used for congestion management as proposed in [19].

In this paper a reactive power flow allocation method has been proposed. After allocation of reactive power, the total cost to be recovered from individual participant towards transaction of reactive power is also allocated to different participant. For allocation power flow tracing technique is used while for cost allocation MVAr-Mile method is used. Results are shown for 6 bus system and IEEE 14 bus system.

\section{DEVELOPED METHODOLOGY}

\subsection{Model for Reactive Power Flow Allocation}

The electrical power system network consists with different component so their behaviors towards tracing of power flow become topological, so power flow by tracing theory is based on true flows in transmission system with consideration of proportional sharing principle. It handles the common issue regarding distribution of VAR (reactive power) flows in a meshed system [12-14]. To determine electricity at the nodes, the nodal power flow based on tracing which generally use implementation of the KCL (Kirchhoff's current law).

To determine the correlation in conjunction with incoming and outgoing flows the proportional sharing and nodal method is adopt. Hence this principle is similar for the validation of true power and reactive power flows. The model proposed and implemented in this paper considered network is as lossless [15], [16].

Let $\ln =1 \ldots \ldots$. e shows entire transmission line in the power system structured, $G_{n}=1 \ldots \ldots . \mathrm{g}$ is entire quantity of generating units and $D=1 \ldots \ldots d$ is the entire quantity of users in the structure. Again $\mathrm{P}_{\mathrm{GG}}=\operatorname{diag}\left(\mathrm{P}_{\mathrm{G} 1}, \mathrm{P}_{\mathrm{G} 2}, \ldots, \mathrm{P}_{\mathrm{Gg}}\right)$ represents generation in diagonal matrix. Thus from [16]

$$
\begin{aligned}
& \mathrm{U}=\mathrm{K}_{\mathrm{m}}{ }^{-1} \mathrm{P}_{\mathrm{L}} \\
& \mathrm{U}^{\mathrm{T}} \mathrm{P}_{\mathrm{GG}}=\left(\mathrm{P}_{\mathrm{G}}\right)^{\mathrm{T}} \text { or } \mathrm{P}_{\mathrm{G}}=\mathrm{P}_{\mathrm{GG}} \mathrm{U}
\end{aligned}
$$

By combining equation (1) and (2)

$$
\mathrm{P}_{\mathrm{G}}=\mathrm{P}_{\mathrm{GG}} \mathrm{K}_{\mathrm{m}}^{-1} \mathrm{P}_{\mathrm{L}}
$$

Obtained matrix $\mathrm{P}_{\mathrm{GG}} \mathrm{K}_{\mathrm{m}}{ }^{-1}$ is called generation production matrix. The generation production matrix is indicated by $\mathrm{GPM}=\left(\mathrm{t}_{\mathrm{ij}}\right)$, i. e., Where,

$$
\begin{aligned}
& \mathrm{GPM}=\mathrm{P}_{\mathrm{GG} \mathrm{K}_{\mathrm{m}}{ }^{-1}} \\
& \mathrm{R}_{\mathrm{i} \rightarrow \mathrm{j}}=\mathrm{t}_{\mathrm{ij}} \mathrm{R}_{\mathrm{Lj}}
\end{aligned}
$$

Here $t_{i j} R_{L j}$ represent the reactive flow contribution of generator situated at bus $i$ to the load at bus $\mathrm{j}$. 
Reactive power allocated to generator placed at bus $i$ share the line $\mathrm{s}-\mathrm{b}$ can be calculated by,

$$
\mathrm{RP}_{\mathrm{i} \rightarrow \mathrm{s}-\mathrm{b}}=\mathrm{t}_{\mathrm{is}} \mathrm{rf}_{\mathrm{s}-\mathrm{b}}
$$

To obtaining the contribution of reactive power by loads similar procedure is repeat.

Where the diagonal matrix $\mathrm{P}_{\mathrm{LL}}=\operatorname{diag}\left(\mathrm{P}_{\mathrm{L} 1}, \mathrm{P}_{\mathrm{L} 2}, \ldots, \mathrm{P}_{\mathrm{Ld}}\right)$ and $\mathrm{EFM}=\mathrm{P}_{\mathrm{LL}}\left(\mathrm{K}_{\mathrm{m}}{ }^{-1}\right)^{\mathrm{T}}$ is the extraction factor matrix of loads to generators [16].

\subsection{Cost Allocation Model for Reactive Flows}

For allocation of reactive power cost following algorithm is developed. For this purpose MVAr-mile method is used. In this model, reactive power charge is allocated with respect to the reactive power base capacity of the transmission line.

If the cost of the line is denoted as $\mathrm{TC}_{\mathrm{s}-\mathrm{b}}$ (in Rs/hr) then Reactive power cost allocated to users is given by: For generator $G_{i}$ full transmission usage cost allocation is given by, $\mathrm{FTRC}_{\mathrm{s}-\mathrm{b}}^{\mathrm{G}_{\mathrm{i}}}$

$$
\mathrm{FTRC}_{\mathrm{s}-\mathrm{b}}^{\mathrm{G}_{\mathrm{i}}}=\frac{\mathrm{RP}_{\mathrm{i} \rightarrow \mathrm{s}-\mathrm{b}}}{\mathrm{rf}_{\text {base } \mathrm{s}-\mathrm{b}}} \times \mathrm{TC}_{\mathrm{s}-\mathrm{b}}
$$

Total transmission Reactive power cost by $\mathrm{TRC}_{\mathrm{f}} \mathrm{G}_{\mathrm{i}}$ allocated to generator $G_{i}$ is given by:

$$
\mathrm{TRC}_{\mathrm{f}}^{\mathrm{G}_{\mathrm{i}}}=\sum_{\mathrm{ln}=1}^{\mathrm{e}} \mathrm{FTRC}_{\mathrm{ln}}^{\mathrm{G}_{\mathrm{i}}}
$$

Similarly for Load $\mathrm{L}_{\mathrm{h}}$ full transmission usage cost allocation is given by, $\mathrm{FTUC}_{\mathrm{s}-\mathrm{b}}^{\mathrm{L}_{\mathrm{h}}}$

$$
\mathrm{FTRC}_{\mathrm{s}-\mathrm{b}}^{\mathrm{L}_{\mathrm{h}}}=\frac{\mathrm{RP}_{\mathrm{j} \rightarrow \mathrm{s}-\mathrm{b}}}{\mathrm{rf}_{\text {base } \mathrm{s}-\mathrm{b}}} \times \mathrm{TC}_{\mathrm{s}-\mathrm{b}}
$$

Total transmission Usage cost $\mathrm{TRC}_{\mathrm{f}}{ }^{\mathrm{L}_{\mathrm{h}}}$ allocated to Load $\mathrm{L}_{\mathrm{h}}$

$$
\mathrm{TRC}_{\mathrm{f}}^{\mathrm{L}_{\mathrm{h}}}=\sum_{\mathrm{ln}=1}^{\mathrm{e}} \mathrm{FTRC}_{\ln }^{\mathrm{L}_{\mathrm{h}}}
$$

\subsection{Partial Recovery Model}

Partial recovery model provide cost recovery with respect to rated reactive power capacity of transmission line. given by:

If the cost of the line is denoted as $\mathrm{TC}_{\mathrm{s}-\mathrm{b}}$ (in $\mathrm{Rs} / \mathrm{hr}$ ) then reactive power cost allocated to users is

For generator $G_{i}$, partial transmission usage cost allocation is given by $\operatorname{PTRC}_{s-b}^{G_{i}}$

$$
\operatorname{PTRC}_{\mathrm{s}-\mathrm{b}}^{\mathrm{G}_{\mathrm{i}}}=\frac{\mathrm{RP}_{\mathrm{i} \rightarrow \mathrm{s}-\mathrm{b}}}{\text { rf }_{\text {rcap s-b }}} \times \mathrm{TC}_{\mathrm{s}-\mathrm{b}}
$$

Total transmission reactive power cost by partial recovery model $\mathrm{TRC}_{\mathrm{p}}{ }^{\mathrm{G}_{\mathrm{i}}}$ allocated to generator $\mathrm{G}_{\mathrm{i}}$

$$
\mathrm{TRC}_{\mathrm{p}} \mathrm{G}_{\mathrm{i}}=\sum_{\mathrm{ln}=1}^{\mathrm{e}} \mathrm{PTRC}_{\ln }^{\mathrm{G}_{\mathrm{i}}}
$$

Similarly for load $L_{h}$, partial transmission reactive power cost allocation is given byPTRC ${ }_{s-b}^{L_{h}}$

$$
\mathrm{PTRC}_{\mathrm{s}-\mathrm{b}}^{\mathrm{L}_{\mathrm{h}}}=\frac{\mathrm{RP}_{\mathrm{j} \rightarrow \mathrm{s}-\mathrm{b}}}{\mathrm{rf}_{\text {rcap s-b }}} \times \mathrm{TC}_{\mathrm{s}-\mathrm{b}}
$$

Total transmission reactive power cost $\mathrm{TRC}_{\mathrm{p}}{ }^{\mathrm{L}_{\mathrm{h}}}$ allocated to load $\mathrm{L}_{\mathrm{h}}$

$$
\operatorname{TRC}_{\mathrm{p}}{ }^{\mathrm{L}_{\mathrm{h}}}=\sum_{\mathrm{ln}=1}^{\mathrm{e}} \mathrm{PTRC}_{\ln }^{\mathrm{L}_{\mathrm{h}}}
$$


The mathematical formulation in Equation 4 shows the contribution of active power of generator's to load in network. Contribution of reactive flow in line by generator can be obtained by mathematical formulation given in Equation 5.

\section{RESULTS AND ANALYSIS}

The presented model is implemented on standard 14 buses IEEE network and 6 bus sample network shown in Fig.1 to test their feasibility and effectiveness. The programming code is developed in MATLAB tool and results are obtained. Under MATLAB tool firstly power system components such as generator, transmission line and loads are modeled for the test system. Newton-Raphson method is used to determine power flow. The line flow limits were also checked out during the power flow. As the restructuring process in power system going on from a decade, trading of real power in power market are carried out while as a responsibility of system operator toward maintaining system security, stability and reliable operation play an important role. To achieve system operator importance, voltage and reactive power comes to the picture. In this paper, the reactive power contributions of demands have been determined using power flow tracing methods. In this perspective, the influence of total reactive power flow through the line is taken for the analysis.

The proposed model is implemented on test network with 6 buses and 14 buses to show their feasibility. First of all reactive power flows are allocated to loads at normal power flow condition by using modified Kirchhoff matrices methodology given in Table I for 6 bus system. For this purpose equation 5 is used. Allocation of the cost to be recovered from individual participant toward reactive power flow through the transmission network under normal operating condition is also done.

\subsection{Sample 6 Bus System}

The single line diagram of the sample 6 bus system is shown in Figure 1. It contains 3 generator buses and 3 load buses. The data is at 100 MVA base. Table 1 shows about line flows and cost for 6 bus system. Table 2 shows about allocated reactive power of different loads for 6 bus system. Table 3 shows about cost allocated to different loads for 6 bus system.

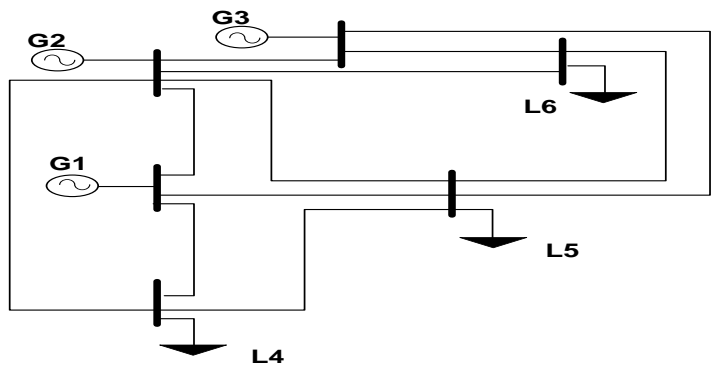

Figure 1. Single line diagram of sample 6 bus system
Table 1. Line Flows and Cost For 6 Bus System

\begin{tabular}{ccc} 
Line & Flow(pu) & Cost (Rs/hr) \\
\hline $1-2$ & 0.142 & 223.61 \\
$1-4$ & 0.227 & 206.16 \\
$1-5$ & 0.149 & 310.49 \\
$2-3$ & 0.075 & 254.95 \\
$2-4$ & 0.496 & 111.8 \\
$2-5$ & 0.185 & 316.23 \\
$2-6$ & 0.153 & 211.9 \\
$3-5$ & 0.269 & 286.36 \\
$3-6$ & 0.645 & 101.98 \\
$4-5$ & 0.023 & 447.21 \\
$5-6$ & 0.063 & 316.23 \\
Total & & 2786.92 \\
\hline
\end{tabular}

Table 2. Allocated Reactive Power of Different Loads for 6 Bus System

\begin{tabular}{ccc}
\hline $\begin{array}{c}\text { Allocated Reactive } \\
\text { Power to Load4 }(\mathrm{pu})\end{array}$ & $\begin{array}{c}\text { Allocated Reactive } \\
\text { Power to Load5 }(\mathrm{pu})\end{array}$ & $\begin{array}{c}\text { Allocated Reactive } \\
\text { Power to Load6 }(\mathrm{pu})\end{array}$ \\
\hline 0.0846 & 0.0771 & 0.0169 \\
0.1353 & 0.1232 & 0.0270 \\
0.0888 & 0.0809 & 0.0178 \\
0.0212 & 0.0130 & 0.0213 \\
0.1403 & 0.0860 & 0.1412 \\
0.0523 & 0.0321 & 0.0527 \\
0.0433 & 0.0265 & 0.0435 \\
0.0000 & 0.0793 & 0.1862 \\
0.0000 & 0.1902 & 0.4465 \\
0.0198 & 0.0012 & 0.0000 \\
0.0000 & 0.0612 & 0.0015 \\
\hline
\end{tabular}


Table 3. Cost Allocated to Different Loads for 6 Bus System

\begin{tabular}{ccc}
\hline $\begin{array}{c}\text { Charge allocated to } \\
\text { Load4(Rs/hr) }\end{array}$ & $\begin{array}{c}\text { Charge allocated } \\
\text { to Load5(Rs/hr) }\end{array}$ & $\begin{array}{c}\text { Charge allocated to } \\
\text { Load6(Rs/hr) }\end{array}$ \\
\hline 133.2212 & 121.4108 & 26.61274 \\
122.8786 & 111.8895 & 24.52123 \\
185.0437 & 168.5815 & 37.09209 \\
72.06587 & 44.19133 & 72.4058 \\
31.62407 & 19.38468 & 31.82694 \\
89.39908 & 54.87018 & 90.08282 \\
59.96908 & 36.70163 & 60.24608 \\
0 & 84.41765 & 198.2165 \\
0 & 30.07224 & 70.59546 \\
384.9895 & 23.3327 & 0 \\
0 & 307.1949 & 7.529286 \\
\hline
\end{tabular}

\subsection{IEE 14 Bus System}

The single line diagram of the IEEE 14 bus system is shown in Figure 2. It contains 2 generator buses and 12 load buses. The data is at 100 MVA base. Table 4 shows about line flows and cost for 14 bus system. Table 5 shows about allocated reactive power of different loads for 14 bus system. Table 6 shows about cost allocated to different loads for 14 bus system.

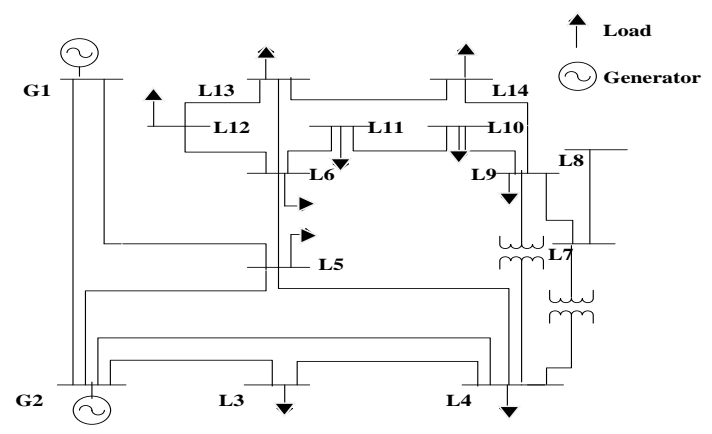

Table 4. Line Flows and Cost for 14 Bus System

\begin{tabular}{cccccc}
\hline S.No. & $\begin{array}{c}\text { Flow } \\
\text { (MVAR) }\end{array}$ & $\begin{array}{c}\text { Cost } \\
\text { (Rs/hr) }\end{array}$ & S.No. & $\begin{array}{c}\text { Flow } \\
\text { (MVAR) }\end{array}$ & $\begin{array}{c}\text { Cost } \\
\text { (Rs/hr) }\end{array}$ \\
\hline 1 & 63.774 & 62.26 & 11 & 6.4 & 220.41 \\
2 & 39.797 & 229.49 & 12 & 2.918 & 283.81 \\
3 & 28.848 & 203.47 & 13 & 8.821 & 146.1 \\
4 & 19.862 & 185.65 & 14 & 0 & 176.15 \\
5 & 17.173 & 182.97 & 15 & 13.065 & 110.01 \\
6 & 0.359 & 183.69 & 16 & 1.531 & 90.29 \\
7 & 8.641 & 44.18 & 17 & 1.961 & 298.77 \\
8 & 15.371 & 209.12 & 18 & 4.378 & 208.86 \\
9 & 10.438 & 556.18 & 19 & 1.111 & 297.92 \\
10 & 33.236 & 252.02 & 20 & 3.528 & 387.73 \\
\hline
\end{tabular}

Figure 2. Single line diagram of IEE 14 bus system

Table 5. Allocated Reactive Power of Different Loads for 14 Bus System

\begin{tabular}{ccccccccccccc}
\hline L3 & L4 & L5 & L6 & L7 & L8 & L9 & L10 & L11 & L12 & L13 & L14 \\
\hline 24.0395 & 12.8888 & 2.185 & 3.22 & 0 & 0 & 7.9544 & 2.526 & 1.0205 & 1.776 & 3.9481 & 4.2157 \\
15.0014 & 8.043 & 1.3635 & 2.0094 & 0 & 0 & 4.9638 & 1.5763 & 0.6368 & 1.1083 & 2.4637 & 2.6308 \\
14.7957 & 5.5619 & 0.4933 & 0.727 & 0 & 0 & 3.4325 & 0.8517 & 0.2304 & 0.401 & 0.8914 & 1.4631 \\
10.1869 & 3.8294 & 0.3397 & 0.5005 & 0 & 0 & 2.3633 & 0.5864 & 0.1586 & 0.2761 & 0.6137 & 1.0073 \\
8.8078 & 3.3109 & 0.2937 & 0.4328 & 0 & 0 & 2.0434 & 0.507 & 0.1372 & 0.2387 & 0.5306 & 0.8709 \\
0.359 & 0 & 0 & 0 & 0 & 0 & 0 & 0 & 0 & 0 & 0 & 0 \\
1.7808 & 3.5804 & 0 & 0 & 0 & 0 & 2.2097 & 0.3799 & 0 & 0 & 0 & 0.6902 \\
3.1677 & 6.369 & 0 & 0 & 0 & 0 & 3.9307 & 0.6758 & 0 & 0 & 0 & 1.2278 \\
2.1511 & 4.325 & 0 & 0 & 0 & 0 & 2.6692 & 0.4589 & 0 & 0 & 0 & 0.8338 \\
3.6432 & 7.325 & 2.2603 & 3.331 & 0 & 0 & 4.5207 & 1.9757 & 1.0557 & 1.8373 & 4.0843 & 3.2028 \\
0 & 0 & 0 & 1.6032 & 0 & 0 & 0 & 0.5768 & 0.5081 & 0.8843 & 1.9657 & 0.8619 \\
0 & 0 & 0 & 0.731 & 0 & 0 & 0 & 0.263 & 0.2317 & 0.4032 & 0.8963 & 0.393 \\
0 & 0 & 0 & 2.2097 & 0 & 0 & 0 & 0.795 & 0.7003 & 1.2188 & 2.7093 & 1.1879 \\
0 & 0 & 0 & 0 & 0 & 0 & 0 & 0 & 0 & 0 & 0 \\
0 & 0 & 0 & 0 & 0 & 0 & 8.8022 & 1.5133 & 0 & 0 & 0 & 2.7496 \\
0 & 0 & 0 & 0 & 0 & 0 & 1.0315 & 0.1773 & 0 & 0 & 0 & 0.3222 \\
0 & 0 & 0 & 0 & 0 & 0 & 1.3212 & 0.2271 & 0 & 0 & 0 & 0.4127 \\
0 & 0 & 0 & 0 & 0 & 0 & 0 & 4.378 & 0 & 0 & 0 \\
0 & 0 & 0 & 0 & 0 & 0 & 0 & 0 & 0 & 0.8653 & 0.1708 & 0.0749 \\
0 & 0 & 0 & 0 & 0 & 0 & 0 & 0 & 0 & 0 & 2.4527 & 1.0753 \\
\hline
\end{tabular}


Table 6. Cost Allocated to Different Loads for 14 Bus System

\begin{tabular}{|c|c|c|c|c|c|c|c|c|c|c|c|}
\hline L3 & L4 & L5 & L6 & L7 & L8 & L9 & L10 & L11 & L12 & L13 & L14 \\
\hline 23.468 & 12.582 & 2.133 & 3.143 & 0 & 0 & 7.765 & 2.466 & 0.996 & 1.733 & 3.854 & 4.115 \\
\hline 86.505 & 46.380 & 7.862 & 11.587 & 0 & 0 & 28.623 & 9.089 & 3.672 & 6.391 & 14.206 & 15.170 \\
\hline 104.356 & 39.229 & 3.479 & 5.127 & 0 & 0 & 24.210 & 6.007 & 1.625 & 2.828 & 6.287 & 10.319 \\
\hline 95.216 & 35.793 & 3.175 & 4.678 & 0 & 0 & 22.089 & 5.481 & 1.482 & 2.580 & 5.736 & 9.415 \\
\hline & 35.27603 & 3.12923 & 4.611274 & & & 21.7714 & 5.40183 & 1.4617 & 2.54323 & 5.65328 & 9.27901 \\
\hline 93.842 & 639 & 1293 & 442 & 0 & 0 & 3761 & 9516 & 99569 & 2924 & 6089 & 7819 \\
\hline 183.69 & 0 & 0 & 0 & 0 & 0 & 0 & 0 & 0 & 0 & 0 & 0 \\
\hline 9.104 & 18.305 & 0 & 0 & 0 & 0 & 11.297 & 1.942 & 0 & 0 & 0 & 3.528 \\
\hline 43.096 & 86.649 & 0 & 0 & 0 & 0 & 53.476 & 9.194 & 0 & 0 & 0 & 16.704 \\
\hline 114.619 & 230.453 & 0 & 0 & 0 & 0 & 142.226 & 24.452 & 0 & 0 & 0 & 44.4283 \\
\hline 27.625 & 55.543 & 17.139 & 25.258 & 0 & 0 & 34.279 & 14.981 & 8.005 & 13.931 & 30.970 & 24.286 \\
\hline 0 & 0 & 0 & 55.212 & 0 & 0 & 0 & 19.864 & 17.498 & 30.454 & 67.696 & 29.683 \\
\hline 0 & 0 & 0 & 71.098 & 0 & 0 & 0 & 25.579 & 22.535 & 39.215 & 87.175 & 38.223 \\
\hline 0 & 0 & 0 & 36.598 & 0 & 0 & 0 & 13.167 & 11.598 & 20.186 & 44.873 & 19.674 \\
\hline 0 & 0 & 0 & 0 & 0 & 0 & 0 & 0 & 0 & 0 & 0 & 0 \\
\hline 0 & 0 & 0 & 0 & 0 & 0 & 74.116 & 12.742 & 0 & 0 & 0 & 23.152 \\
\hline 0 & 0 & 0 & 0 & 0 & 0 & 60.832 & 10.456 & 0 & 0 & 0 & 19.001 \\
\hline 0 & 0 & 0 & 0 & 0 & 0 & 201.292 & 34.600 & 0 & 0 & 0 & $\begin{array}{c}62.8772 \\
9679\end{array}$ \\
\hline 0 & 0 & 0 & 0 & 0 & 0 & 0 & 208.86 & 0 & 0 & 0 & 0 \\
\hline 0 & 0 & 0 & 0 & 0 & 0 & 0 & 0 & 0 & 232.034 & 45.800 & 20.084 \\
\hline 0 & 0 & 0 & 0 & 0 & 0 & 0 & 0 & 0 & 0 & 269.553 & 118.176 \\
\hline
\end{tabular}

In Opportunity cost method the total cost of reactive power including capacitor cost is $7.31 \$ / \mathrm{hr}$ or $467.84 \mathrm{Rs} / \mathrm{hr}$ and in case of Triangle method total cost of reactive power including capacitor cost is 267 \$/hr or $16020 \mathrm{Rs} / \mathrm{hr}$ reported in [20] while the total cost allocated obtained from proposed model as shown in Table VI for IEEE 14 bus system is $69.21 \$ / \mathrm{hr}$ or $4152.94 \mathrm{Rs} / \mathrm{hr}$ which is more acceptable to attract the investor in deregulated power market as compared to Opportunity cost method and Triangle method.

\section{CONCLUSION}

The main objective of the model proposed in this paper is to allocate reactive power for each load based upon the proportion of reactive power flow through the transmission line as per demand by the load. The reactive power flow tracing is done by constructing reactive power flow matrix.

The main reason behind the reactive power flow is the inductive loading at the load end; hence by using MVAr-Mile method the cost of this reactive power flowing is allocated to loads. Power system network is very large so this need to have additional information regarding reactive power injected by different sources as well as shunt admittance of the transmission line, the tracing of power flow scheme becomes as effective tool to achieve that. For reliable and stable operation of power system the reactive power economics play a vital role. By allocating the reactive power flow cost by proposed model, total embedded cost associated with the transmission line can be recovered and the size of reactive power sources installations such as capacitor bank, SVC and FACTS devices can be easily done.

\section{REFERENCES}

[1] Abdorreza Rabiee, Haidor Alishayanfer, Nibamjady Iee, Power And Enginering Magazine pp.18-32 January/February 2009.

[2] Peter W. Sauer. What is Reactive power? Power systems Engineering Research Center, Department of Electrical and Computer Engineering , university of Illinois at Urbana- Champaign, September 16,2003.

[3] Harinder Pal Singh, Yadwinder Singh Brar, D. P. Kothari, “Combined Active and Reactive Power Dispatch Using Particle Swarm Optimization”, Proceedings of Informing Science \& IT Education Conference (InSITE) 2014.

[4] Wood, A.J., and Wollenberg, B.F., “ Power generation, operation, and control ”, (Wiley, New York, 1996, 2nd Edn.).

[5] Ferdinand Gubina, David Grgic, Ivo Bani, “ Method for Determining the Generators Share in a Consumer Load ”, IEEE Transactions on Power Systems, vol. 15, no. 4, November 2000.

[6] Y. Dai, X.D. Liu, Y.X. Ni, F.S. Wen, Z.X. Han, C.M. Shen, Felix F. Wu, “ A cost allocation method for reactive power service based on power flow tracing ”, Electric Power Systems Research, vol.64, pp.59-65, 2003.

[7] D. Thukaram C. Vyjayanthi, "Relative electrical distance concept for evaluation of network reactive power and loss contributions in a deregulated system:, IET Gener. Transm. Distrib., vol. 3, no.11, pp. 1000-1019, 2009.

[8] Seyed Mohammad Hossein Nabavi, Somayeh Hajforoosh, Sajad Hajforosh, Nazanin Alsadat Hosseinipoor, “ Using Tracing Method for Calculation and Allocation of Reactive Power Cost ”, International Journal of Computer Applications , vol. 13, no. 2, pp.14-17, 2011. 
[9] Hussain Shareef, Mohd. Wazir Mustafa, Saifulnizam Abd Khalid, Azhar Khairuddin, Akhtar Kalam, Amanullah Maung Than Oo, "Real and Reactive Power Transfer Allocation Utilizing Modified Nodal Equations” International Journal of Emerging Electric Power Systems, vol. 9, no. 6, article 4, 2008

[10] Hermagasantos Zein, Erwin Dermawan "Cost Allocation of Transmission Losses in Electric Market Mechanism" TELKOMNIKA, vol.10, no.2, , pp. 211-218, June 2012.

[11] Hogan, W , “ Markets in Real Electric Networks Require Reactive Prices ”, The Energy Journal, vol.14, no.3 pp.171-200, 1993.

[12] J. W. Lamont and J. Fu, “ Cost analysis of reactive power support ”, IEEE Transactions on Power Systems, vol. 14, no. 3, pp. 890-898, Aug. 1999.

[13] Baughman, M. L. and Siddiqi , S. N. , "Real Time Pricing of Reactive Power: Theory and Case Study Results", IEEE Trans. on Power Systems,vol. 6, no.1, pp. 23-29, 1991.

[14] Schweppe, F. C., M. C. Caramanis, R. D. Tabors, and R. E. Bohn , Spot Pricing of Electricity, Kluwer Academic Publishers, Boston. 1998

[15] Bialek J.W., Kattuman P.A.,“ Proportional sharing assumption in tracing methodology”, IEE Proceedings Generation transmission Distribution, vol.151, no.4, pp.526-532, July 2004.

[16] Kaigui Xie, Jiaqi Zhou, Wenyuan Li " Analytical model and algorithm for tracing active power flow based on extended incidence matrix ”, Electric Power Systems Research, vol.79, pp. 399-405, 2009

[17] Enshaee A., Enshaee P., “ New reactive power flow tracing and loss allocation algorithm for grids using matrix calculation ” Electric Power and Energy System, vol.87,pp.89-98,2017

[18] S.K. Gupta, R.Bansal, Partibha Sharma, Mukesh Saini "Power Trading and Congestion Management through Real Power Rescheduling Using Unified Power Flow Controller”, Indonesian Journal of Electrical Engineering and Informatics, vol. 2, no. 4, pp. 151-160, December 2014.

[19] Sawan Sen, Priyanka Roy, Abhijit Chakrabarti, Samarjit Sengupta “ Generator Contribution Based Congestion Management using Multiobjective Genetic Algorithm ”, TELKOMNIKA, vol.9, no.1, pp. 1-8, April 2011

[20] Abbas Ketabi , Ahmad Alibabaee , R. Feuillet " Application of the ant colony search algorithm to reactive power pricing in an open electricity market ”, Electrical Power and Energy Systems, vol.32, pp.622-628, 2010. 